\title{
The effect of reinforcement ratios on composite slabs in fire
}

1 Anthony K. Abu PhD

Lecturer, Department of Civil and Natural Resources Engineering, University of Canterbury, Christchurch, New Zealand

2 Ian W. Burgess PhD

Professor, Department of Civil and Structural Engineering, University of Sheffield, Sheffield, UK
3 Roger J. Plank PhD

Emeritus Professor, School of Architectural Studies, University of Sheffield, Sheffield, UK
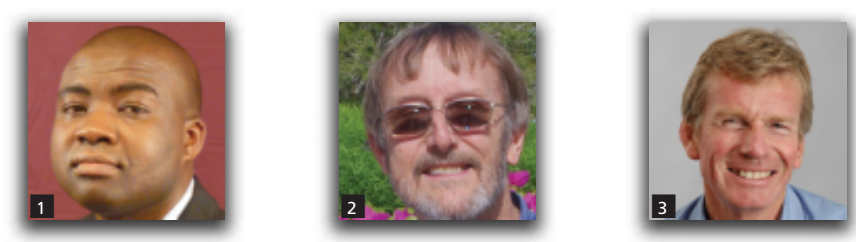

Public-domain software currently allows designers to incorporate the enhancement of fire resistance due to tensile membrane action of composite slabs into their analysis of building behaviour in fire. Based on the Bailey-BRE Method, it enhances slab capacity by optimising reinforcement size in order to carry its fire limit state loading at the required fire resistance time. The method assumes that protected edge beams maintain vertical support of the slab at its boundaries, only allowing for failure of compartmentation integrity by tensile fracture of mid-panel reinforcement or by concrete crushing at the corners. However, these beams deflect under their increased loading in fire, which can cause premature structural failure of the panel. It is imperative to determine the real contribution of reinforcement to tensile membrane action, considering the loss of edge support. This paper presents a series of finite element studies conducted with Vulcan, compared with the generic simplified method and the public-domain software, to determine the influence of reinforcement on the failure of slab panels at elevated temperatures.

\section{Introduction}

Recent development trends aimed at ensuring the fire resistance of structures have encouraged increased use of performancebased approaches, which are now often categorised as structural fire engineering. These methods attempt to model, to different degrees, the actual behaviour of a three-dimensional structure, taking account of realistic fire exposure scenarios, the loss of some load from the ultimate to the fire limit state, actual material behaviour at elevated temperatures and interaction between various parts of the structure. Assessment of the real behaviour of structures in fire has shown that the traditional practice of protecting all exposed steelwork can be wasteful in steel-framed buildings with composite floors, since partially protected composite floors can generate sufficient strength to carry considerable loading at the fire limit state, through a mechanism known as tensile membrane action, provided that fire compartmentation is maintained and that connections are designed with sufficient strength and ductility. Tensile membrane action is a load-bearing mechanism of thin slabs under large vertical displacement, in which an induced radial membrane tension field in the central area of the slab is balanced by a peripheral ring of compression. In this mechanism the slab capacity increases with increasing deflection. This load-bearing action offers economic advantages for composite floor construction, since a large number of the steel floor beams can be left unprotected. The conditions necessary for the effective use of this mechanism are two-way bending and vertical support along the slab's edges. In the current structural fire engineering implementation of performance-based methods in the UK, buildings are designed to comply with a list of agreed acceptance criteria, including a range of typical fires, causing realistic temperatures of the beams, columns and slabs, allowable deflection limits to avoid integrity failure, and acceptable connection forces at elevated temperatures. These requirements make non-linear finite-element methods ideal for structural fire engineering assessments, as the behaviour of an entire building (or a substantial part of it) can be monitored. However, numerical analyses are time-consuming processes, and so simplified methods which provide good preliminary estimates of structural behaviour are always an advantage.

The Building Research Establishment (BRE) membrane action method, devised by Bailey and Moore (2000), is one such procedure, which assesses composite slab capacity in fire by estimating the enhancement which tensile membrane action makes to the flexural capacity of the slab. It is based on rigidplastic theory with large change of geometry. The method 
assumes that a composite floor is divided into rectangular fireresisting 'slab panels' (see Figure 1), composed internally of parallel unprotected composite beams, vertically supported at their edges, which usually lie on the building's column grid. In fire the unprotected steel beams within these panels lose strength, and their loads are progressively borne by the highly deflected thin concrete slab in biaxial bending. The increase in slab resistance is calculated as an enhancement of the traditional small-deflection yield-line capacity of the slab panel. This enhancement is dependent on the slab's aspect ratio, and increases with deflection. The method, initially developed for isotropically reinforced slabs (Bailey, 2000), has been extended to include orthotropic reinforcement (Bailey, 2003). A more recent update by Bailey and Toh (2007a) considers more realistic in-plane stress distributions and compressive failure of concrete slabs. The deflection of the slab has to be limited in order to avoid an integrity (breach of compartmentation) failure. Failure is defined either as tensile fracture of the reinforcement in the middle of the slab panel or as compressive crushing of concrete at its corners. The deflection limit, shown as Equation 1, is defined on the basis of thermal and mechanical deflections and test observations

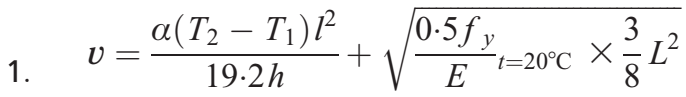

in which

$v$ is the allowable vertical displacement

$\alpha$ is the coefficient of thermal expansion of concrete

$T_{2}$ is the slab bottom surface temperature

$T_{1}$ is the slab top surface temperature

$L$ is the length of the longer span of the slab

$l$ is the length of the shorter span of the slab
$H$ is the effective depth of the slab, as given in BS EN1994-1-2 Annex D (BSI, 2005)

$f_{\mathrm{y}}$ is reinforcement yield stress

$E$ is the elastic modulus of the reinforcement

The first term of Equation 1 accounts for the 'thermal bowing' deflection, assuming a linear temperature gradient through the depth of a horizontally unrestrained concrete slab. The second part considers deflections caused by applying an average tensile mechanical reinforcement strain, of $50 \%$ of its yield strain at $20^{\circ} \mathrm{C}$, across the longer span of the slab, assuming that its horizontal span stays unchanged. This part of the allowable deflection is further limited to $l / 30$. In normal structural mechanics terms this superposition of two components of the total deflection is not acceptable, because of their incompatible support assumptions, but nevertheless it is the deflection limit used. The limiting deflection has been calibrated to accord with large-scale fire test observations at Cardington (Bailey, 2000). In particular, in Equation $1 \alpha$ is taken as $18 \times 10^{-6} /{ }^{\circ} \mathrm{C}$, the recommended constant value (BSI, 2005) for simple calculation, for normalweight concrete, and the difference $\left(T_{2}-T_{1}\right)$ between the bottom and top slab surface temperatures is taken as $770^{\circ} \mathrm{C}$ for fire resistance periods up to $90 \mathrm{~min}$, and $900^{\circ} \mathrm{C}$ for $2 \mathrm{~h}$, based on the test observations (Bailey, 2001).

A primary advantage of the method is the simplicity of its calculations; it is, therefore, suitable for implementation in spreadsheet software. The Steel Construction Institute (SCI) has further developed the method, and has implemented it in the Microsoft Excel-based spreadsheet TSLab (Newman et al., 2006). Whereas the basic method limits slab deflections using the assumption of nominal temperatures based on the Cardington fire tests, the vertical deflection limit in TSLab is calculated by using $T_{2}$ and $T_{1}$ values obtained from a thermal analysis of the slab

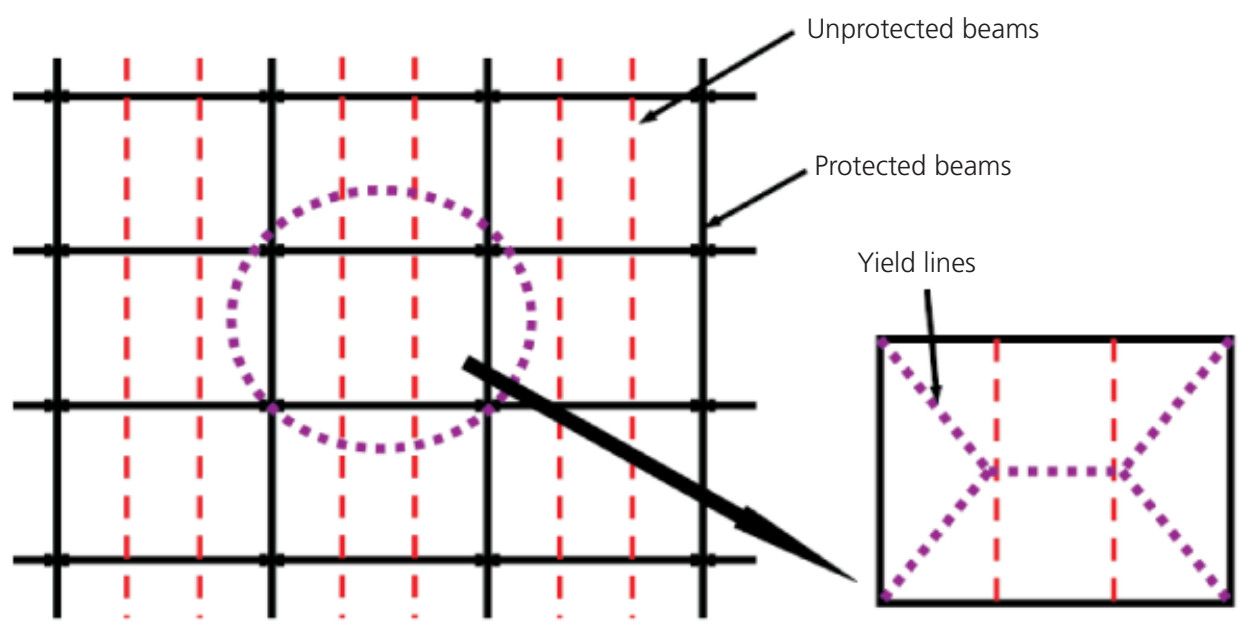

(a)

(b)

Figure 1. Schematic diagram of the Bailey-BRE method:

(a) composite floor slab; (b) slab panel 
cross-section. A plot of the limiting deflections from the two processes, for a $9 \mathrm{~m} \times 9 \mathrm{~m} \times 130 \mathrm{~mm}$ deep normal-weight concrete slab panel cast on ComFlor 60 steel decking, is shown in Figure 2. The deflection limits are compared against the general (span/20) deflection criterion, which is the upper limit in the standard fire test (BSI, 1987). It is observed that, although TSLab embodies the calculation process of the Bailey-BRE method, there are differences between their limits. A direct comparison of the two approaches has also indicated (Toh and Bailey, 2007) that there are discrepancies between the original Bailey-BRE equations and their interpretation in TSLab. On inspection it is evident that, not only does the Bailey-BRE limit assume a constant temperature difference between the top and bottom surfaces of the slab, but it also uses a higher coefficient of thermal expansion for normal-weight concrete than that used in TSLab.

The Bailey-BRE method and TSLab both assume that full vertical support is available at all the slab panel boundaries. In practice, this is achieved by protecting the slab panel's edge beams, which must lie on the column grid of the building (see Figure 1). When the unprotected secondary beams lose most of their strength at very high temperatures there is a re-distribution of the loads carried by these protected edge beams; the primary beams lose load because of the loss of load capacity of the unprotected beams whose ends they support, whereas the protected secondary beams gain load by tending to support the floor area with which they would be associated in a non-composite two-way-spanning slab. The Bailey-BRE method, therefore, requires that the protected secondary beams are designed for their increased load ratios at the fire limit state. As the protected beams lose strength with time, and the load re-distribution at the fire limit state causes increased deflections at the panel boundaries, the assumption of continuous vertical support along the panel's edges becomes progressively less valid. The use of yieldline theory as the baseline for the strength enhancement also dictates that a slab panel's capacity increases with increased

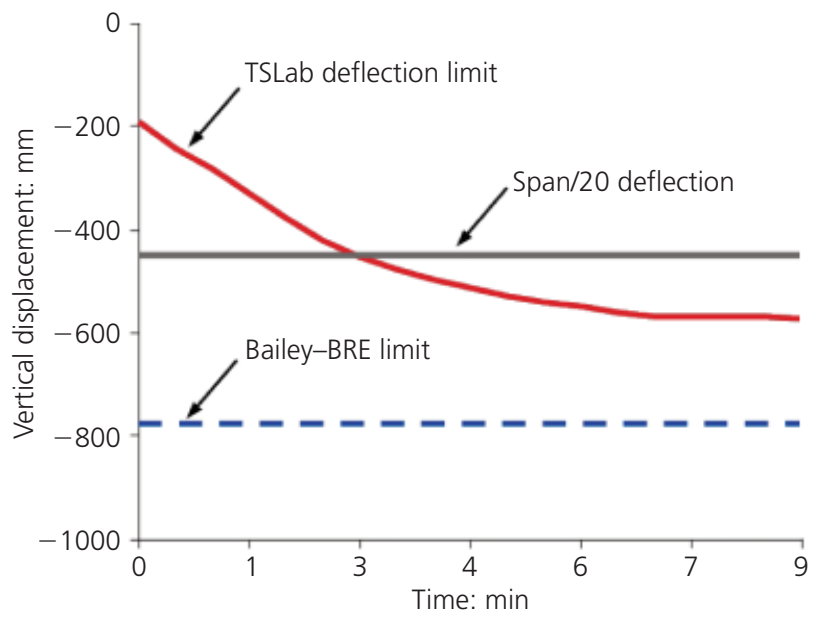

Figure 2. Slab deflection limits reinforcement area, unless duly arrested by a compressive failure criterion, as identified by Bailey and Toh (2007a). However, since the primary requirements for tensile membrane action to be mobilised are double-curvature bending, large deflections and vertical edge support, excessive deflections of the protected edge beams can result in the double-curvature bending being converted into single-curvature bending. In consequence the panel may fail structurally in sagging, so that the reinforcement's tensile strength is not usefully employed.

Previous studies by Bailey and Toh (2007b), Huang et al. (2002, 2004b) and Foster (2006) have compared the BaileyBRE method both with experiments and with more detailed analytical approaches based on finite-element analysis. These have highlighted a number of shortcomings in the simplified method. One which has attracted particular interest is the effect of increased slab reinforcement ratios. The Bailey-BRE method indicates that a modest increase in the reinforcement ratio can result in a disproportionately large increase in composite slab capacity, whereas the finite-element analyses indicate a much more limited increase. The finite-element studies by Huang et al. (2002, 2004b) examined slabs with some continuity along their edges. The Bailey-BRE method was developed assuming that slab reinforcement fractures in hogging over its edge supports, leaving simply supported edges which allow horizontal pull-in. Recent research (Abu, 2009; Abu et al., 2008) has shown that the behaviour of edge beams affects the failure mode and failure time of slab panels in fire. For panels which lie on the perimeter of a building, the lack of in-plane and rotational restraint along their free edges implies a reliance on the selection of reinforcement area and adequate sizing and protection of edge beams.

The current paper extends the investigation of the effects of edge beam behaviour on slab panel failure (Abu et al., 2008) by examining the effects of increasing reinforcement areas. The study is conducted by comparing results from Vulcan finiteelement analyses of isolated slab panels with those of the Bailey-BRE method, in order to determine the influence of reinforcement area on slab panels at elevated temperatures, and to identify the range of applicability of the method's assumptions. The paper does not include material type, ductility, surface texture or orthotropic reinforcement effects on slab panel failure. It is clear that these could significantly influence the behaviour of these panels, as observed by Foster et al. (2004) and Bailey and Toh (2007b). With practical structural fire engineering design in mind, the comparisons are done with respect to the deflection criteria of TSLab, the original Bailey-BRE method and the standard fire test $(l / 20)$.

\section{Studies comparing Vulcan and the Bailey-BRE method}

The three slab panel layouts shown in Figure 3 were used for the structural analyses. The $9 \mathrm{~m} \times 6 \mathrm{~m}, 9 \mathrm{~m} \times 9 \mathrm{~m}$ and $9 \mathrm{~m} \times 12 \mathrm{~m}$ panels were designed for $60 \mathrm{~min}$ standard fire resistance, assum- 


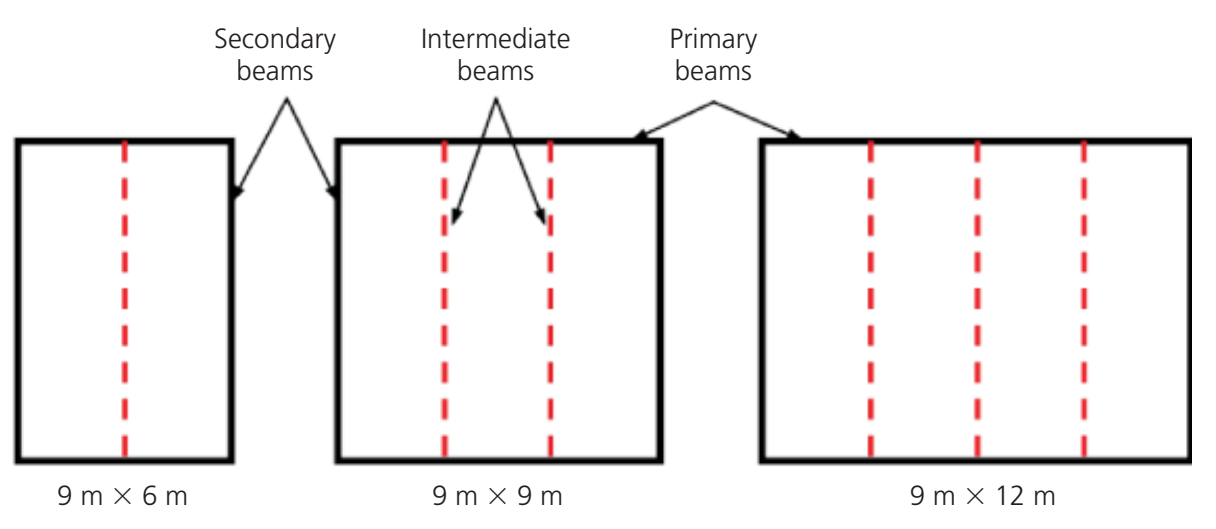

Protected

--- Unprotected

Figure 3. Slab panel sizes

ing normal-weight concrete of cube strength $40 \mathrm{MPa}$ and a characteristic imposed load of $5.0 \mathrm{kN} / \mathrm{m}^{2}$, plus $1.7 \mathrm{kN} / \mathrm{m}^{2}$ for ceilings and services. Using the trapezoidal slab profile shown in Figure 4, the requirements of SCI P-288 (Newman et al., 2006) and the slab specifications given in Table 1, the floor beams were designed according to BS 5950-3 (BSI, 1990) and BS 5950-8 (BSI, 2003), assuming full composite action between steel and concrete, and simple support to all beams, in line with common British engineering practice. The 'office' usage class is assumed, so that the partial safety factors applied to loadings are 1.4 (dead) and 1.6 (imposed) for ultimate limit state and 1.0 and 0.5 for fire limit state. The assumed uniform cross-section temperatures of the protected beams were limited to $550^{\circ} \mathrm{C}$ at $60 \mathrm{~min}$. The ambient and elevated temperature designs resulted in specification of the steel beam sizes shown in Table 2 .

As previously mentioned, the assessment in this paper is presented as a comparison between the Bailey-BRE method and Vulcan finite-element analysis. Both the Bailey-BRE method and TSLab implicitly assume that the edges of a slab panel do not deflect vertically. The progressive loss of strength of the intermediate unprotected beams is captured by a reduction in the steel yield stress with temperature. The reduced capacity of the unprotected beams (interpreted as an equivalent floor load intensity) is compared with the total applied load at the fire limit

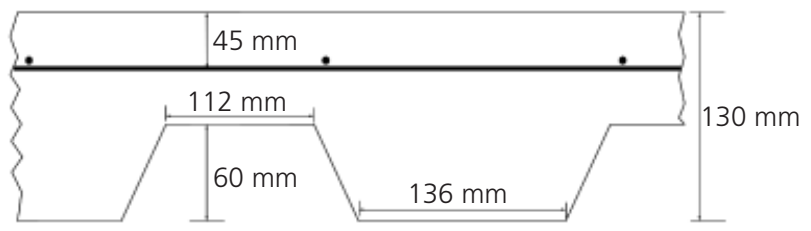

Figure 4. Concrete slab cross-section, showing the trapezoidal decking profile

\begin{tabular}{lccc}
\hline Slab panel size & $9 \mathrm{~m} \times 6 \mathrm{~m}$ & $9 \mathrm{~m} \times 9 \mathrm{~m}$ & $9 \mathrm{~m} \times 12 \mathrm{~m}$ \\
\hline Dead load: $\mathrm{kN} / \mathrm{m}^{2}$ & 4.33 & 4.33 & 4.33 \\
Live load: $\mathrm{kN} / \mathrm{m}^{2}$ & 5.00 & 5.00 & 5.00 \\
Additional load: $\mathrm{kN}$ & 14.00 & 37.00 & 49.00 \\
Beam design factor & 0.77 & 1.00 & 0.83 \\
Min. mesh size & $\mathrm{A} 193$ & $\mathrm{~A} 193$ & $\mathrm{~A} 252$
\end{tabular}

Table 1. Slab panel requirements (R60)

state to determine the vertical displacement required by the reinforced concrete slab (whose yield-line capacity also reduces with temperature) to generate sufficient enhancement to carry the applied load. The required displacement is then limited to an allowable value. The Vulcan finite-element analysis, on the other hand, properly models the behaviour of protected edge beams, with full vertical support available only at the corners of each panel. Vulcan (Huang et al., 2003a, 2003b, 2004a) is a threedimensional geometrically non-linear specialised finite-element program which also considers non-linear elevated temperature material behaviour. Non-linear layered rectangular shell elements, capable of modelling both membrane and bending effects, are used to represent reinforced concrete slab behaviour, while beam or column behaviour is adequately modelled with segmented nonlinear beam-column elements. The different layers and segments of the elements can be assigned different temperatures, with corresponding thermal strains and stress-strain characteristics in fire, thereby giving the elements the capability to model the effects of differential thermal expansion in a structure. Concrete failure follows a biaxial peak-stress interaction surface assuming 'smeared' cracking.

The analyses are initially performed with the standard isotropic reinforcing mesh sizes A142, A193, A252 and A393. These are, 


\begin{tabular}{lllccc}
\hline Slab panel size & Beam type & Beam section & Load ratio & $\begin{array}{c}\text { Limiting } \\
\text { temperature: }{ }^{\circ} \mathrm{C}\end{array}$ & $\begin{array}{c}\text { Temperature at } \\
60 \mathrm{~min}:{ }^{\circ} \mathrm{C}\end{array}$ \\
\hline $9 \mathrm{~m} \times 6 \mathrm{~m}$ & Secondary & $356 \times 171 \times 57$ UB & 0.426 & 636 & 548 \\
& Primary & $406 \times 178 \times 60$ UB & 0.452 & 627 & 549 \\
$9 \mathrm{~m} \times 9 \mathrm{~m}$ & Secondary & $356 \times 171 \times 67$ UB & 0.442 & 630 & 550 \\
$9 \mathrm{~m} \times 12 \mathrm{~m}$ & Primary & $533 \times 210 \times 101$ UB & 0.446 & 629 & 548 \\
& Secondary & $406 \times 178 \times 67$ UB & 0.447 & 629 & 548 \\
& Primary & $610 \times 305 \times 179$ UB & 0.471 & 620 & 547
\end{tabular}

Table 2. Protected beam design data (R60)

respectively, composed of $6 \mathrm{~mm}, 7 \mathrm{~mm}, 8 \mathrm{~mm}$ and $10 \mathrm{~mm}$ diameter bars of $500 \mathrm{~N} / \mathrm{mm}^{2}$ yield strength, all at $200 \mathrm{~mm}$ spacing. The required mid-slab vertical displacements of the Bailey-BRE approach and the corresponding predicted deflections of the Vulcan analyses are compared with the TSLab, BRE and standard fire test $(l / 20)$ deflection limits; the structural properties of the two models are selected to be consistent with the assumptions of the Bailey-BRE method (Bailey, 2001). The results are also compared with a simple slab panel failure mechanism (Abu, 2009), shown in Figure 5. This mechanism determines the time at which the horizontally unrestrained slab panel loses its load-bearing capacity owing to biaxial tensile membrane action, and goes into single-curvature bending (simple plastic folding), due to the loss of plastic bending capacity of the protected edge beams. Using a work-balance equation, it predicts when the parallel arrangements of primary or secondary (intermediate unprotected and protected secondary) composite beams lose their ability to carry the applied fire limit state load because of their temperature-induced strength reductions. The expressions for plastic folding failure across the primary and secondary beams are shown in Equations 2 and 3, respectively

Primary beam failure

2. $\frac{w a b}{2}-\frac{4 \sum M_{\mathrm{p}}}{a} \geqslant 0$

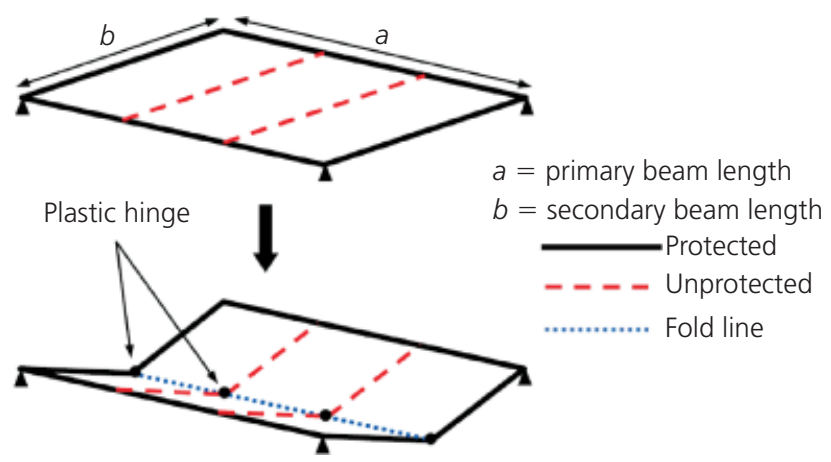

Figure 5. Slab panel folding mechanism
Secondary beam failure

3. $\frac{w a b}{2}-\left(\frac{4 \sum M_{\mathrm{s}}}{b}+\frac{4 \sum M_{\mathrm{u}}}{b}\right) \geqslant 0$

In the equations above $a$ and $b$ are the lengths of the primary and secondary beams, $w$ is the applied fire limit state floor loading and $M_{\mathrm{u}}, M_{\mathrm{s}}$ and $M_{\mathrm{p}}$ are the temperature-dependent capacities of the unprotected, protected secondary and protected primary composite beams, respectively, at any given time.

The observations from early analyses led to a more detailed investigation of the combined effects of edge-beam stability and the reinforcement ratios on slab panel failure in fire. For the most like-against-like comparison against Bailey-BRE and TSLab, the slab panel temperature conditions generated by TSLab needed to be reproduced in the Vulcan analyses. The unprotected intermediate beam temperatures from TSLab were also applied directly to the other two models. TSLab generates weighted mean temperatures of the slab top surface, bottom surface and reinforcement. These were applied directly to the Bailey-BRE models. The same could not be assumed for the Vulcan analyses, as fictitious temperatures would have needed to be assumed for the other layers in the slab's cross-section. These assumptions could adversely influence both thermal and stress-related strains in the model. Thus, following the earlier research (Abu et al., 2008), a one-dimensional thermal analysis of the average depth $(100 \mathrm{~mm})$ of the profiled slab was performed with the software FPRCBC-T (Huang et al., 1996). The temperatures (shown in Figure 6) correlated very closely with those from TSLab. These temperatures were applied in the Vulcan analyses.

\section{Results}

The results of the comparative analyses, shown in Figures 7-9, show slab panel deflections with different reinforcement mesh sizes. For ease of comparison, in each graph the A142reinforced panels are shown as dotted lines, while those reinforced with A193, A252 and A393 are shown as dashed, solid and chain-dot lines, respectively. For clarity the required vertical displacements for the Bailey-BRE method and the 


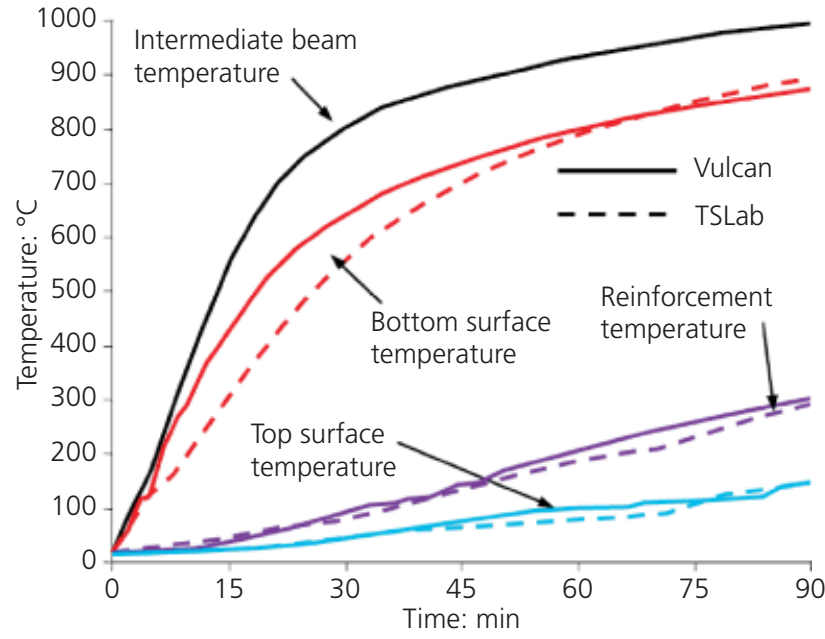

Figure 6. Beam and slab temperature evolution for R60 design

predicted actual displacements from the Vulcan analyses are shown on separate graphs ((a) and (b)) for each slab panel size. Displacements predicted by Vulcan at the centres of the slab panels are also shown relative to the deflections of the midpoints of the protected secondary beams in graphs (c) for comparison. This illustration is appropriate because the deflected slab profile in the Bailey-BRE method relates to non-deflecting edge beams; a more representative comparison with Vulcan therefore requires a relationship between its slab deflection and deflected edge beams. Furthermore, this approach has the advantage of de-congesting the figures for more accurate interpretation. The limiting deflections, and the times at which plastic folding of the slab, including the protected edge beams, takes place (referred to as the 'collapse time') are also shown. Regardless of the layout of a panel, it can be observed that the single-curvature fold line always occurs across secondary beams; the associated collapse times are indicated by the vertical lines in the figures. The temperatures of the various intermediate and protected secondary beams at failure for the three slab panel layouts are shown in Table 3. Apart from the $9 \mathrm{~m} \times 6 \mathrm{~m}$ panel it can be seen that failure occurs when the protected secondary beams are below their own limiting temperatures (see Table 2). The results are discussed in terms of slab aspect ratio (defined as 'longer slab span'/'shorter slab span'), and the panel capacity with respect to each limiting deflection. It is to be expected that square slab panels should have the highest enhancement of their capacity owing to tensile membrane action.

\subsection{Slab panel analyses}

\subsection{1 $9 \mathrm{~m} \times 6 \mathrm{~m}$ slab panel}

SCI P-288 (Newman et al., 2006) specifies A193 as the minimum reinforcing mesh required for $60 \mathrm{~min}$ of fire resistance. Figure 7(a) shows the required Bailey-BRE displacements together with the deflection limits and the slab panel collapse time. A193 mesh satisfies the BRE limit, but is inadequate for $60 \mathrm{~min}$ of fire

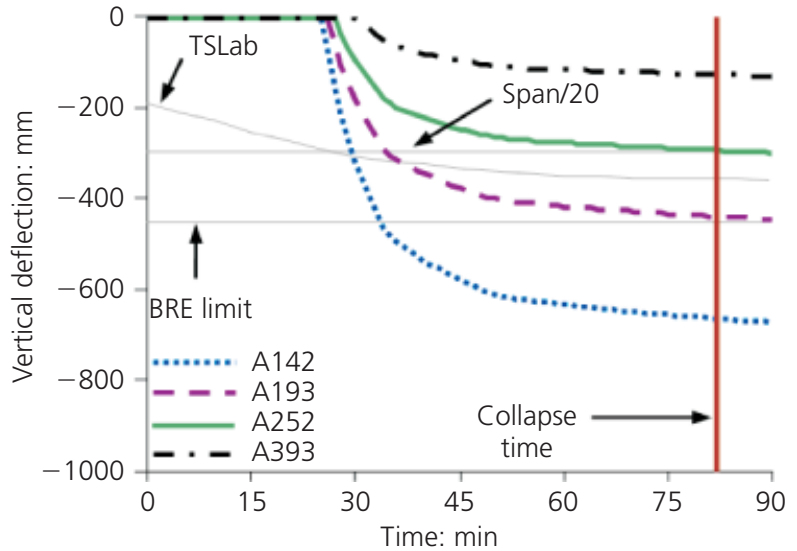

(a)

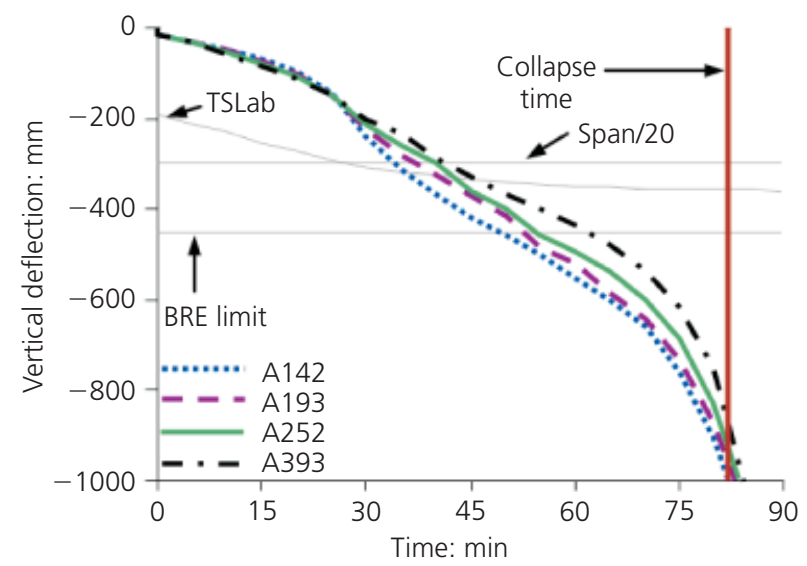

(b)

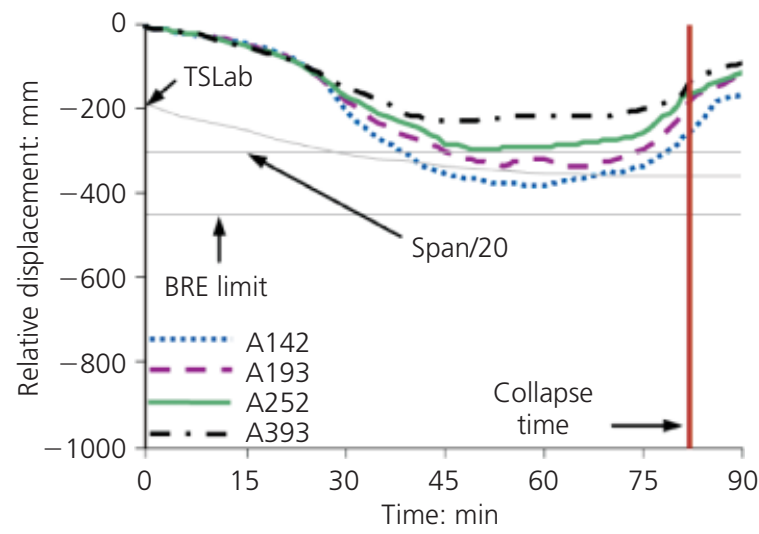

(c)

Figure 7. (a) Bailey-BRE method - $9 \mathrm{~m} \times 6 \mathrm{~m}$ slab panel, required vertical displacements (R60). (b) Vulcan $-9 \mathrm{~m} \times 6 \mathrm{~m}$ slab panel, central vertical displacements (R60). (c) Vulcan $9 \mathrm{~m} \times 6 \mathrm{~m}$ slab panel, displacements of slab centre relative to protected secondary beams (R60)

resistance according to TSLab. A252 and A393 satisfy all deflection criteria. It should be noted that there is no indication of failure of the panels according to Bailey-BRE, even when the collapse time is approached. This is partly attributable to neglect of the behaviour of the edge beams; runaway failure of Bailey- 


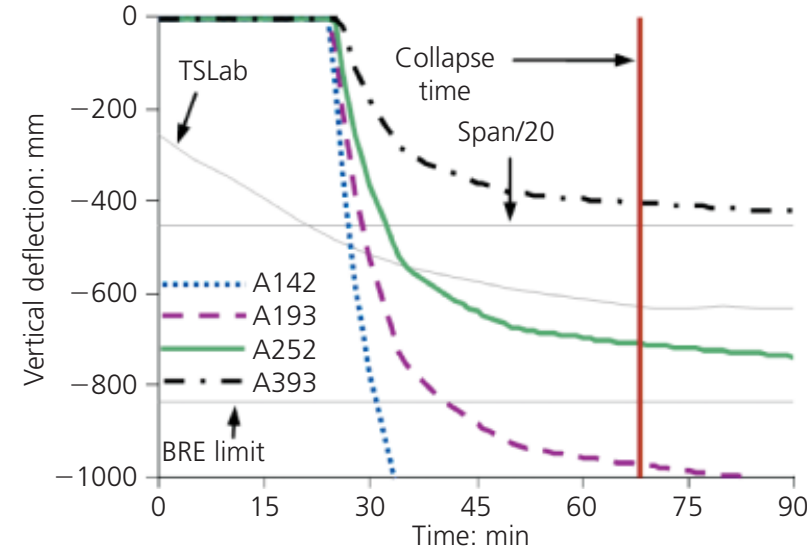

(a)

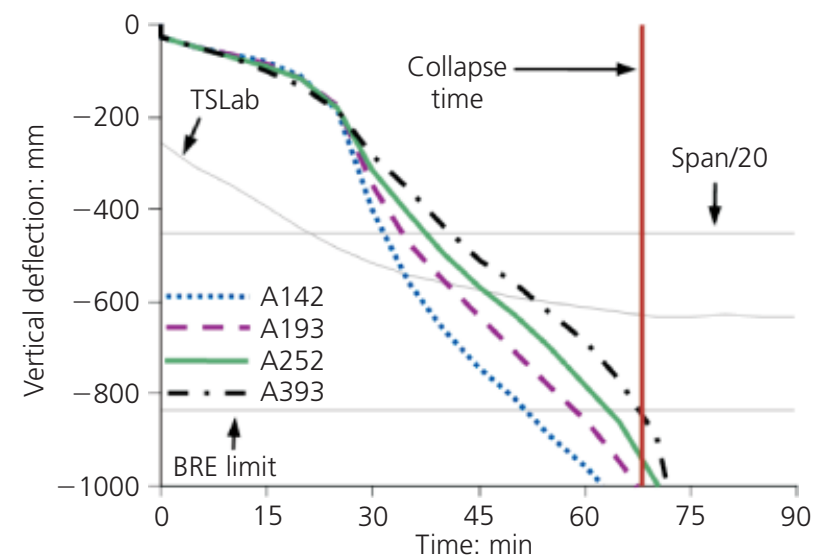

(b)

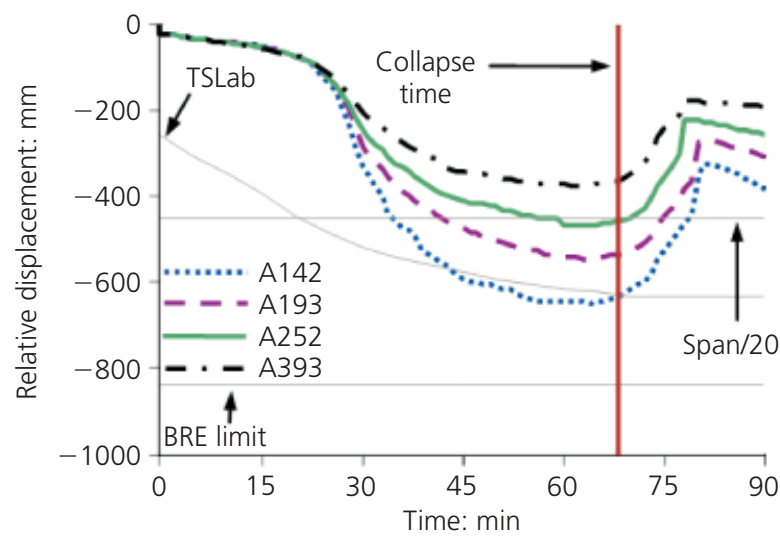

(c)

Figure 8. (a) Bailey-BRE method $-9 \mathrm{~m} \times 12 \mathrm{~m}$ slab panel, required vertical displacements (R60). (b) Vulcan $-9 \mathrm{~m} \times 12 \mathrm{~m}$ slab panel, central vertical displacements (R60). (c) Vulcan $9 \mathrm{~m} \times 12 \mathrm{~m}$ slab panel, displacements of slab centre relative to protected secondary beams (R60)

BRE panels is only evident in the required deflections when the reinforcement has lost a very significant proportion of its strength. Vulcan predicted deflections are shown in Figure 7(b). It is observed that the A393 mesh just satisfies the BRE limiting deflection at $60 \mathrm{~min}$. It can also be seen that the deflections of the

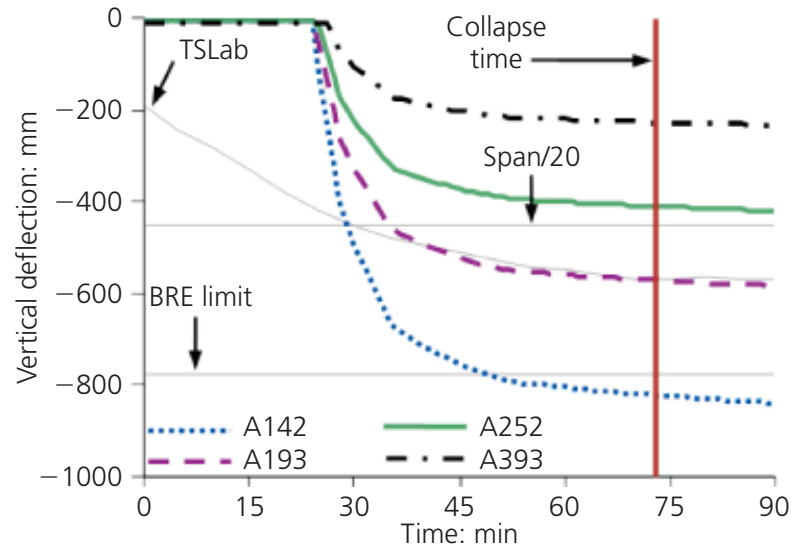

(a)

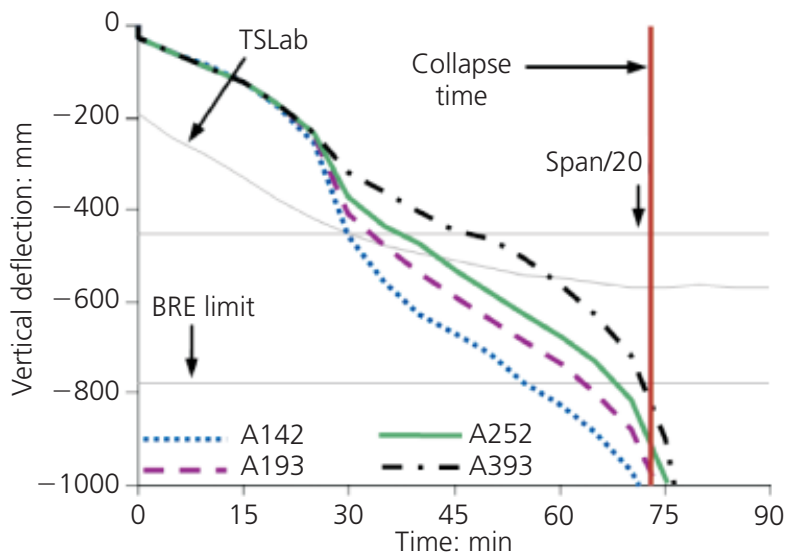

(b)

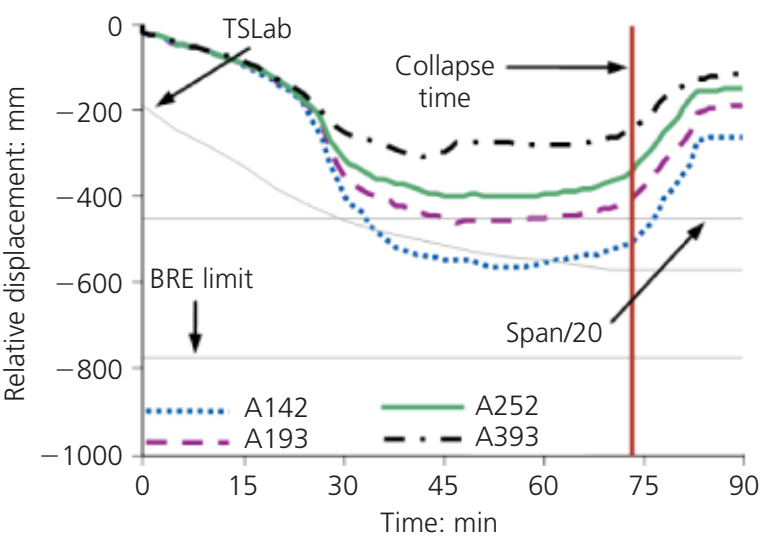

(c)

Figure 9. (a) Bailey-BRE method $-9 \mathrm{~m} \times 9 \mathrm{~m}$ slab panel, required vertical displacements (R60). (b) Vulcan $-9 \mathrm{~m} \times 9 \mathrm{~m}$ slab panel, central vertical displacements (R60). (c) Vulcan -

$9 \mathrm{~m} \times 9 \mathrm{~m}$ slab panel, displacements of slab centre relative to protected secondary beams (R60).

various Vulcan analyses converge at the 'collapse time' (82 min) of the simple slab panel folding mechanism. This clearly indicates the loss of bending capacity of the protected secondary beams. Comparing Figures 7(a) and 7(b), the Bailey-BRE method predicts substantial enhancement of the panel fire 


\begin{tabular}{llccc}
\hline & Slab panel size & Failure time & $\begin{array}{c}\text { Intermediate beam } \\
\text { temperature: }{ }^{\circ} \mathrm{C}\end{array}$ & $\begin{array}{c}\text { Secondary beam } \\
\text { temperature: }{ }^{\circ} \mathrm{C}\end{array}$ \\
\hline R60 & $9 \mathrm{~m} \times 6 \mathrm{~m}$ & $82 \mathrm{~min}$ & 983 & 663 \\
& $9 \mathrm{~m} \times 9 \mathrm{~m}$ & $73 \mathrm{~min}$ & 963 & 621 \\
$9 \mathrm{~m} \times 12 \mathrm{~m}$ & $68 \mathrm{~min}$ & 952 & 594
\end{tabular}

Table 3. Slab panel failure times and corresponding secondary

beam temperatures (R60)

resistance with increasing reinforcement mesh size, while Vulcan shows a marginal increase. Also the Bailey-BRE approach is found to be conservative with A142 and A193 and unconservative with the larger mesh sizes. As the slab panel edges in the Bailey-BRE and TSLab methods are assumed to stay vertical, the required displacements shown in Figure 7(a) should be considered as relative values. Relative displacements of the slab centre with respect to the deflected protected secondary beams in the Vulcan model are shown in Figure 7(c). If this principle is accepted, a comparison of Figures 7(a) and 7(c) indicates that the Bailey-BRE predictions for A142 and A193 are conservative. Results for A252 in these two figures correlate closely. However, for A393, the Bailey-BRE method appears unconservative. Further examination of Figure 7(c) shows that A252 and A393 meshes satisfy all the limiting deflection criteria, while A193 is adequate according to the TSLab and BRE limit criteria. It should be noted that a reduction in the relative displacement is an indication of incipient runaway failure of the slab panel, since the deflection of the protected secondary beams begins to catch up with that of the unprotected intermediate beams, forming a single-curvature failure mechanism by folding of the whole panel.

\subsection{2 $9 \mathrm{~m} \times 12 \mathrm{~m}$ slab panel}

In the previously discussed $9 \mathrm{~m} \times 6 \mathrm{~m}$ slab panel the secondary beams are longer than the primary beams. In the $9 \mathrm{~m} \times 12 \mathrm{~m}$ layout this is reversed. However, its large overall size requires its minimum mesh size to be A252 (Newman et al., 2006). From the required displacements shown in Figure 8(a), A252 mesh satisfies a 60 min fire resistance requirement with respect to the BaileyBRE limit. It is observed from this graph that increasing the mesh size from A252 to A393 results in an increase in the slab panel capacity from about $37 \mathrm{~min}$ to over $90 \mathrm{~min}$, relative to the TSLab deflection limit. The same cannot be said for the Vulcan results (Figure 8(b)), which show very little increase in capacity with larger meshes. It is shown that A252 and A393 meet the fire resistance requirement at $60 \mathrm{~min}$ with respect to the BRE limiting deflection. It is also observed that the Vulcan deflections appear to converge on a slab panel collapse time of $68 \mathrm{~min}$. At failure, the protected secondary beams are at $594^{\circ} \mathrm{C}$, which is considerably below their limiting temperature. Note that, in this study, sufficient protection is applied to all protected beams to ensure that their design temperature (at $60 \mathrm{~min}$ ) is limited to $550^{\circ} \mathrm{C}$. Typically in an economic design, beams would be protected to a temperature just below their critical temperature at the required fire resistance time. This would potentially cause structural failure of the panel earlier than $68 \mathrm{~min}$. The displacement of the centre of the panel relative to the mid-span deflection of the protected secondary beams is shown in Figure 8(c). A393 mesh is seen to satisfy all deflection criteria, while A193 and A252 satisfy the TSLab and BRE limits. Comparing Figures 8(a) and 8(c), the Bailey-BRE method is the more conservative of the simplified procedures. However, it is important to note that the use of relative deflections may require either heavy protection of edge beams or limitation of their deflections to standard fire test deflection limits $(l / 20)$.

\subsection{3 $9 \mathrm{~m} \times 9 \mathrm{~m}$ slab panel}

Figure 9 shows results for the $9 \mathrm{~m} \times 9 \mathrm{~m}$ slab panel, plotted together with the edge beam collapse mechanism and the three deflection criteria. The discrepancy between the Bailey-BRE limit and TSLab is evident once again; the recommended minimum reinforcement for $60 \mathrm{~min}$ of fire resistance, A193, is adequate with respect to the BRE limit, but fails to meet the TSLab limit. As reported for the other panel layouts, an increase in mesh size results in a disproportionately large increase in the Bailey-BRE panel resistance (Figure 9(a)) while Vulcan (Figure 9(b)) shows a more modest increase. Failure of the protected secondary beams at $73 \mathrm{~min}$ (also Figure 9(b)) limits any contribution the reinforcement might have made to the panel capacity. A comparison of the relative displacements (Figure 9(c)) with the required Bailey-BRE displacements indicates that the latter method is the more conservative for A142 and A193 meshes.

The comparisons in Figures 7-9 show that finite-element modelling indicates only marginal increases in slab panel capacity with increasing reinforcement size. The Bailey-BRE method, on the other hand, shows huge gains in slab panel resistance with larger mesh sizes, even when compared to the relative displacements given by the finite-element analyses. Results for the $9 \mathrm{~m} \times 6 \mathrm{~m}$ and $9 \mathrm{~m} \times 9 \mathrm{~m}$ slab panels have shown that the Bailey-BRE method is conservative with the lower reinforcement sizes, while it overestimates slab panel capacities for higher mesh sizes. The $9 \mathrm{~m} \times 12 \mathrm{~m}$ panel, however, requires higher reinforcement sizes in any case. The Vulcan results show that slab panel capacity is affected more by geometry than by reinforcement area. Better correlations were recorded between the required displacements and relative displacements from the finite-element model than 
with absolute displacements. However, the use of relative displacements in assessing slab panel capacity should be considered in conjunction with an evaluation of the capacity of protected edge beams. There is a need to incorporate the effect of edge beams into the simplified Bailey-BRE analysis, and so a more detailed study of the effect of reinforcement area relative to slab panel failure is now undertaken.

\subsection{Effects of reinforcement ratio}

The comparison in the previous section shows that the BaileyBRE method can predict very high increases of slab panel capacity as a result of small changes in reinforcement area, while Vulcan on the other hand indicates only marginal increases. The fact that the structural response of the protected secondary beams is ignored seems to be the key to this over-optimistic prediction by the Bailey-BRE method. Therefore, to investigate the real contribution of reinforcement ratios, structural failure of the panel as a whole by plastic folding has been incorporated as a further limit to the Bailey-BRE deflection range. Fictitious intermediate reinforcement sizes have been used, in addition to the standard meshes, in order to investigate the effects of increasing reinforcement area on slab panel resistance. The range of reinforcement area is maintained between $142 \mathrm{~mm}^{2} / \mathrm{m}$ and $393 \mathrm{~mm}^{2} / \mathrm{m}$; the additional areas are $166,221,284,318$ and $354 \mathrm{~mm}^{2} / \mathrm{m}$. The investigation in this section examines failure times of the slab panel with respect to the three limiting deflection criteria (TSLab, the generic BRE limit and span/20) normalised with respect to the time to creation of a panel folding mechanism, since this indicates a real structural collapse of the entire slab panel. Results for the $9 \mathrm{~m} \times 6 \mathrm{~m}$, $9 \mathrm{~m} \times 12 \mathrm{~m}$ and $9 \mathrm{~m} \times 9 \mathrm{~m}$ panels are shown in Figure 10. The lightly shaded curves show required deflections from the BaileyBRE method. The deflections predicted by Vulcan are shown as darker curves. The dotted, solid and dashed lines refer, respectively, to failure times with respect to the 'short span/20' criterion, the TSLab deflection limit and the BRE limit.

Figure 10(a) shows how the normalised $9 \mathrm{~m} \times 6 \mathrm{~m}$ slab panel failure times vary with increasing reinforcement mesh size for the 60 min design case. The results confirm the earlier observation of modest increases in slab panel capacity in the finite-element model and over-optimistic predictions in the Bailey-BRE method model. Looking at the BRE limit, the increase in slab panel resistance between reinforcement areas of $142 \mathrm{~mm}^{2} / \mathrm{m}$ and $166 \mathrm{~mm}^{2} / \mathrm{m}$ is $26 \%$. However, increasing the reinforcement area from $166 \mathrm{~mm}^{2} / \mathrm{m}$ to $193 \mathrm{~mm}^{2} / \mathrm{m}$ results in a capacity increases of over $100 \%$. Similar observations are made with respect to the other deflection limits with reinforcement areas above $200 \mathrm{~mm}^{2} / \mathrm{m}$. Vulcan on the other hand registers a maximum capacity increase of only $30 \%$ between $142 \mathrm{~mm}^{2} / \mathrm{m}$ and $393 \mathrm{~mm}^{2} / \mathrm{m}$. A comparison of the two analytical models shows that the Bailey-BRE method is conservative in this case up to a reinforcement area of about $200 \mathrm{~mm}^{2} / \mathrm{m}$ for the $9 \mathrm{~m} \times 6 \mathrm{~m}$ slab panel. A similar trend is observed for the $9 \mathrm{~m} \times 12 \mathrm{~m}$ slab panel (Figure 10(b)). However, this large panel requires a larger area of reinforcement to mobilise tensile membrane action. Thus the conservatism of the Bailey-BRE method

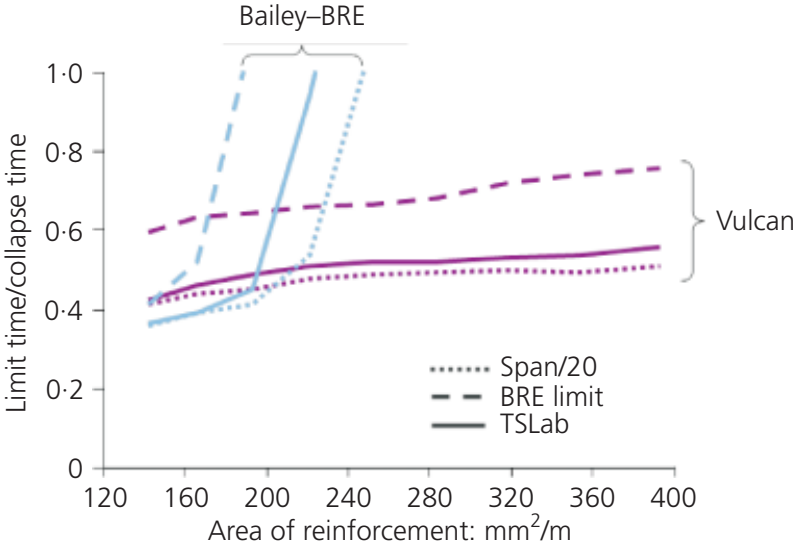

(a)

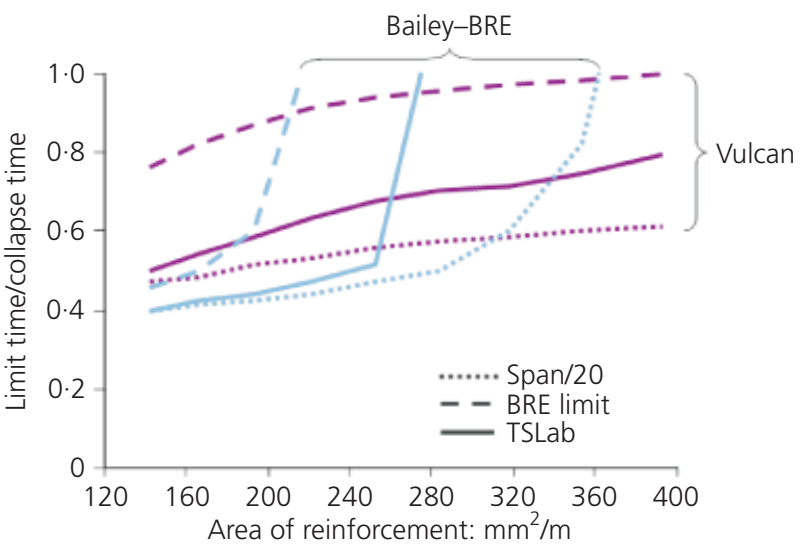

(b)

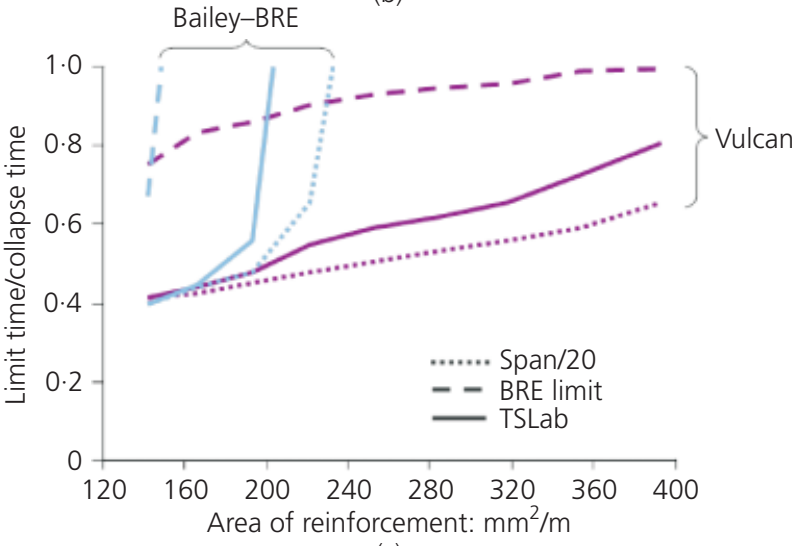

(c)

Figure 10. (a) Bailey-BRE and Vulcan $9 \mathrm{~m} \times 6 \mathrm{~m}$ slab panel comparison (R60). (b) Bailey-BRE and Vulcan $9 \mathrm{~m} \times 12 \mathrm{~m}$ slab panel comparison (R60). (c) Bailey-BRE and Vulcan $9 \mathrm{~m} \times 9 \mathrm{~m}$ slab panel comparison (R60)

extends to about $300 \mathrm{~mm}^{2} / \mathrm{m}$, depending on the selection of the deflection limit. The Vulcan failure times also increase rapidly between $142 \mathrm{~mm}^{2} / \mathrm{m}$ and $250 \mathrm{~mm}^{2} / \mathrm{m}$ and experience a gradual increase thereafter, indicating that a minimum reinforcement area is necessary to realise the effects of tensile membrane action. A comparison of normalised failure times for the $9 \mathrm{~m} \times 9 \mathrm{~m}$ slab panel with respect to reinforcement area is shown in Figure 10(c). 
The effect of the square aspect ratio is evident. The Vulcan analysis records an increase in slab panel capacity of $97 \%$ between $142 \mathrm{~mm}^{2} / \mathrm{m}$ and $393 \mathrm{~mm}^{2} / \mathrm{m}$ relative to the TSLab limit. The Bailey-BRE method on the other hand indicates that a $60 \mathrm{~min}$ slab rating can be achieved with isotropic reinforcement mesh area between $166 \mathrm{~mm}^{2} / \mathrm{m}$ and $250 \mathrm{~mm}^{2} / \mathrm{m}$.

The comparisons in Figure 10 further confirm that the BaileyBRE method is conservative for the lower areas of reinforcement, but is otherwise unconservative. The method depends on the calculation of an enhancement to the small-deflection yield-line capacity, which increases with increasing reinforcement size. Disproportionately higher slab capacities are obtained with higher reinforcement ratios, if the capacity of the protected edge beams is not adequately considered. The results show that the finiteelement analyses give a more logical indication of the contribution of the reinforcement area to slab panel capacity. The Vulcan 60 min analyses show a steady increase in slab resistance with increasing reinforcement area, as they realistically consider the behaviour of edge beams and the failure properties of concrete and reinforcement. For a more general assessment of the effect of reinforcement on slab panel failure, $90 \mathrm{~min}$ and $120 \mathrm{~min}$ fire resistance design scenarios are now examined with Vulcan.

The $9 \mathrm{~m} \times 6 \mathrm{~m}, 9 \mathrm{~m} \times 12 \mathrm{~m}$ and $9 \mathrm{~m} \times 9 \mathrm{~m}$ slab panels are redesigned for these higher fire resistance times by selecting appropriate beam sizes, fire protection and slab thicknesses to ensure that the load ratios of all beams lie between 0.4 and 0.5 , considering increased loadings on the protected secondary beams at the fire limit state. Also, the reinforcement depth is maintained at $45 \mathrm{~mm}$ from the top surface of the slab. Again the fire protection ensures that the protected beam temperatures reach a maximum of $550^{\circ} \mathrm{C}$ at the respective fire resistance times, on exposure to the standard fire curve. The beam specifications for the $90 \mathrm{~min}$ and $120 \mathrm{~min}$ cases are shown in Table 4 . The slab panel collapse times and corresponding intermediate and protected secondary beam temperatures are shown in Table 5. Vulcan failure times for the $9 \mathrm{~m} \times 6 \mathrm{~m}, 9 \mathrm{~m} \times 12 \mathrm{~m}$ and $9 \mathrm{~m} \times 9 \mathrm{~m}$ slab panels with respect to the TSLab, BRE and 'span/20' deflection limits for $60 \mathrm{~min}, 90 \mathrm{~min}$ and $120 \mathrm{~min}$ panels are plotted together in Figure 11. Since the $60 \mathrm{~min}$ designs have already been highlighted in Figure 10, they are shown as thinner lines, in the

\begin{tabular}{|c|c|c|c|c|c|c|}
\hline & Slab panel size & Beam type & Beam section & Load ratio & $\begin{array}{c}\text { Limiting } \\
\text { temperature: }{ }^{\circ} \mathrm{C}\end{array}$ & $\begin{array}{l}\mathrm{R} 90 \text { or } \mathrm{R} 120 \\
\text { temperature: }{ }^{\circ} \mathrm{C}\end{array}$ \\
\hline \multirow{6}{*}{ R90 } & \multirow[t]{2}{*}{$9 \mathrm{~m} \times 6 \mathrm{~m}$} & Secondary & $356 \times 171 \times 57$ UB & 0.440 & 631 & 549 \\
\hline & & Primary & $406 \times 178 \times 60 \cup B$ & 0.453 & 627 & 549 \\
\hline & \multirow[t]{2}{*}{$9 \mathrm{~m} \times 9 \mathrm{~m}$} & Secondary & $356 \times 171 \times 67$ UB & 0.451 & 627 & 550 \\
\hline & & Primary & $533 \times 210 \times 101$ UB & $0 \cdot 447$ & 628 & 549 \\
\hline & \multirow[t]{2}{*}{$9 \mathrm{~m} \times 12 \mathrm{~m}$} & Secondary & $406 \times 178 \times 67$ UB & 0.470 & 621 & 549 \\
\hline & & Primary & $610 \times 305 \times 179$ UB & 0.473 & 620 & 549 \\
\hline \multirow[t]{6}{*}{$\mathrm{R} 120$} & \multirow{2}{*}{$9 \mathrm{~m} \times 6 \mathrm{~m}$} & Secondary & $356 \times 171 \times 57$ UB & $0 \cdot 445$ & 629 & 549 \\
\hline & & Primary & $406 \times 178 \times 60$ UB & $0 \cdot 453$ & 626 & 550 \\
\hline & \multirow[t]{2}{*}{$9 \mathrm{~m} \times 9 \mathrm{~m}$} & Secondary & $356 \times 171 \times 67$ UB & 0.459 & 624 & 550 \\
\hline & & Primary & $533 \times 210 \times 101$ UB & $0 \cdot 452$ & 627 & 549 \\
\hline & \multirow[t]{2}{*}{$9 m \times 12 m$} & Secondary & $457 \times 152 \times 67 \cup B$ & $0 \cdot 447$ & 629 & 550 \\
\hline & & Primary & $686 \times 254 \times 170$ UB & $0 \cdot 454$ & 626 & 550 \\
\hline
\end{tabular}

Table 4. Protected beam design data for R90 and R120

\begin{tabular}{llccc}
\hline & Slab panel size & $\begin{array}{c}\text { Failure time: } \\
\min \end{array}$ & $\begin{array}{c}\text { Intermediate beam } \\
\text { temperature: }{ }^{\circ} \mathrm{C}\end{array}$ & $\begin{array}{c}\text { Secondary beam } \\
\text { temperature: }{ }^{\circ} \mathrm{C}\end{array}$ \\
\hline R90 & $9 \mathrm{~m} \times 6 \mathrm{~m}$ & 124 & 1051 & 673 \\
& $9 \mathrm{~m} \times 9 \mathrm{~m}$ & 113 & 1036 & 637 \\
$\mathrm{R} 120$ & $9 \mathrm{~m} \times 12 \mathrm{~m}$ & 101 & 1018 & 593 \\
& $9 \mathrm{~m} \times 6 \mathrm{~m}$ & 163 & 1103 & 673 \\
& $9 \mathrm{~m} \times 9 \mathrm{~m}$ & 148 & 1083 & 634 \\
& $9 \mathrm{~m} \times 12 \mathrm{~m}$ & 136 & 1067 & 601
\end{tabular}

Table 5. Slab panel failure times and corresponding secondary

beam temperatures (R90 and R120) 


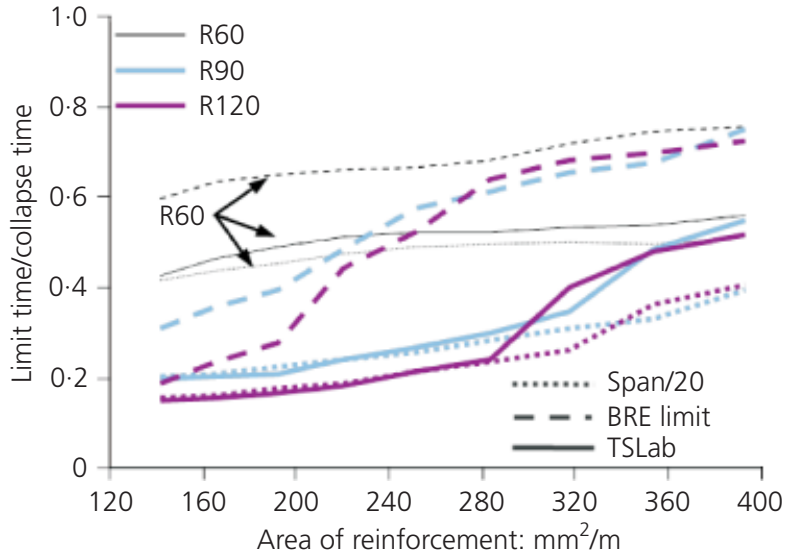

(a)

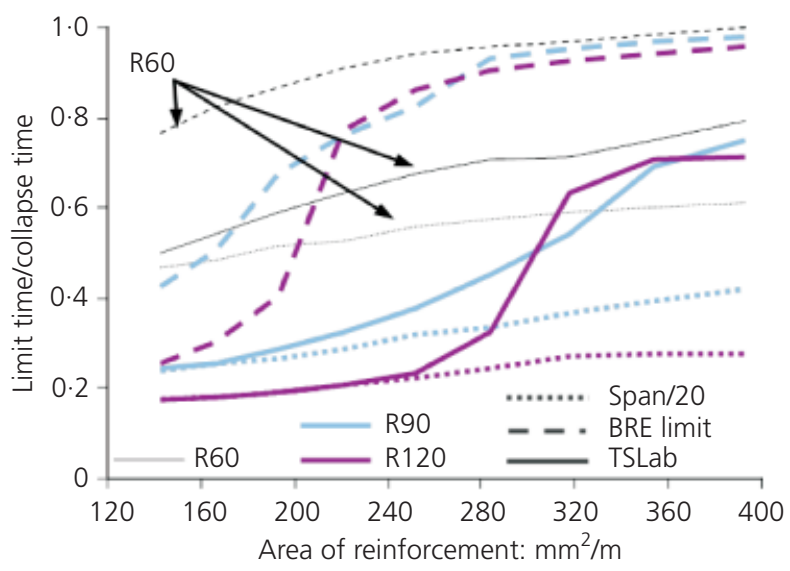

(b)

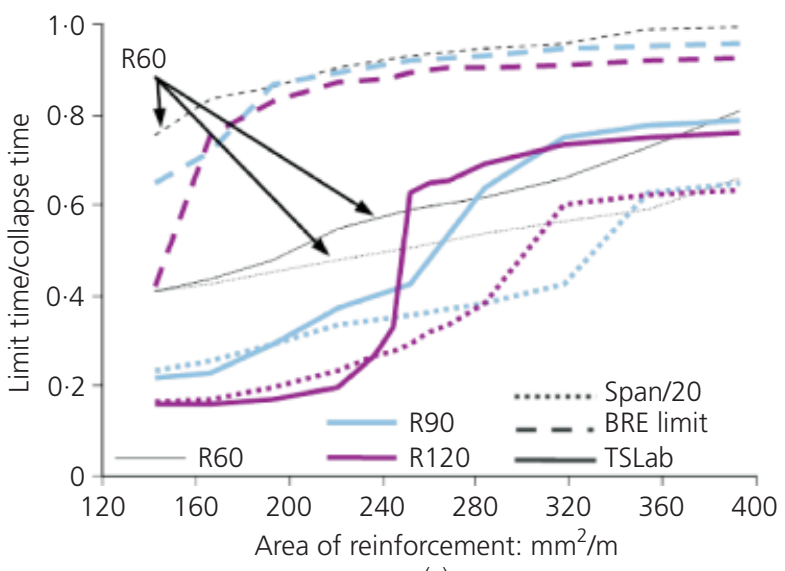

(c)

Figure 11. (a) Vulcan normalised failure times plotted against reinforcement area $-9 m \times 6 \mathrm{~m}$ slab panel. (b) Vulcan normalised failure times plotted against reinforcement area $-9 \mathrm{~m} \times 12 \mathrm{~m}$ slab panel. (c) Vulcan normalised failure times plotted against reinforcement area $-9 \mathrm{~m} \times 9 \mathrm{~m}$ slab panel

background of each figure. The line codings used in the previous figure are maintained for Figure 11.

From Figure 11(a), it is seen that lower reinforcement area does not significantly influence slab panel failure times for the $90 \mathrm{~min}$ and $120 \mathrm{~min}$ cases. Mesh sizes above $280 \mathrm{~mm}^{2} / \mathrm{m}$ show significant increases in capacity with increasing reinforcement. A similar trend is observed in the $9 \mathrm{~m} \times 12 \mathrm{~m}$ slab panel (Figure 11(b)). An examination of the results of the $9 \mathrm{~m} \times 9 \mathrm{~m}$ slab panel in Figure 11(c) reveals a general increase in failure time with increasing reinforcement area. However, it is observed that mesh sizes below $240 \mathrm{~mm}^{2} / \mathrm{m}$ hardly influence slab panel capacity, especially in the higher fire resistance category. To investigate the phenomenon, a further four extra fictitious reinforcement mesh sizes $\left(236.5,244.25,260\right.$ and $\left.268 \mathrm{~mm}^{2} / \mathrm{m}\right)$ are included in the $120 \mathrm{~min} 9 \mathrm{~m} \times 9 \mathrm{~m}$ slab panel analyses. By examining the failure time curve relative to the TSLab deflection limit for the $120 \mathrm{~min}$ design scenario, even with the increased number of reinforcement areas, it is evident that two conditions exist for failure. The same phenomenon is not, however, recorded in the $60 \mathrm{~min}$ case (Figure 10(c)), which shows a continuous increase in slab panel capacity with increasing reinforcement size.

For tensile membrane action to be the most significant loadcarrying mechanism, the unprotected beams need to lose considerable strength. This commences when a temperature of $400^{\circ} \mathrm{C}$ is attained. However, for an unprotected beam load ratio of 0.467 , corresponding to a limiting temperature of $622^{\circ} \mathrm{C}$, the slab panel system behaves as a set of individual composite beams until the stage where the individual unprotected beams lose significant load-bearing resistance and deflect rapidly, ultimately reaching the point where the slab, in biaxial bending, relies on tensile membrane action to bear the applied loading. After reaching the limiting temperature of the composite secondary beams, large deflections develop in the central area of the slab, allowing transfer of load to membrane action of the slab. Typically, the unprotected beams in the $120 \mathrm{~min} 9 \mathrm{~m} \times 9 \mathrm{~m}$ slab panel are at $740^{\circ} \mathrm{C}$ at about $25 \mathrm{~min}$ and deflect rapidly. Lower reinforcement areas are unable to arrest this deflection before the TSLab deflection limit is reached (Figure 12). However, this is not observed with the higher reinforcement areas such as A393, as they contribute more to the initial bending resistance of the slab, thereby allowing it to utilise fully the extra capacity that membrane action provides, hence increasing the failure time. Although the increased thickness in the 120 min panel reduces the thermal gradient in the slab, its restrained in-plane expansion, against much colder perimeter beams, induces higher initial deflections than in the 60 min model. In addition, the $h$ term in Equation 1 increases, thereby reducing the vertical deflection limits of TSLab and BRE, thus causing early 'failure' of the less highly reinforced panels and implying higher minimum reinforcement areas for higher fire resistance times.

In tensile membrane action the extent of the central tensile area is an indication of the tensile capacity of the slab. For a given reinforcement size, an increase in the central tensile area is accompanied by an increase in vertical deflections. Conversely, for a given deflection, the central tensile area is expected to increase with an increase in the reinforcement area. In the studies 


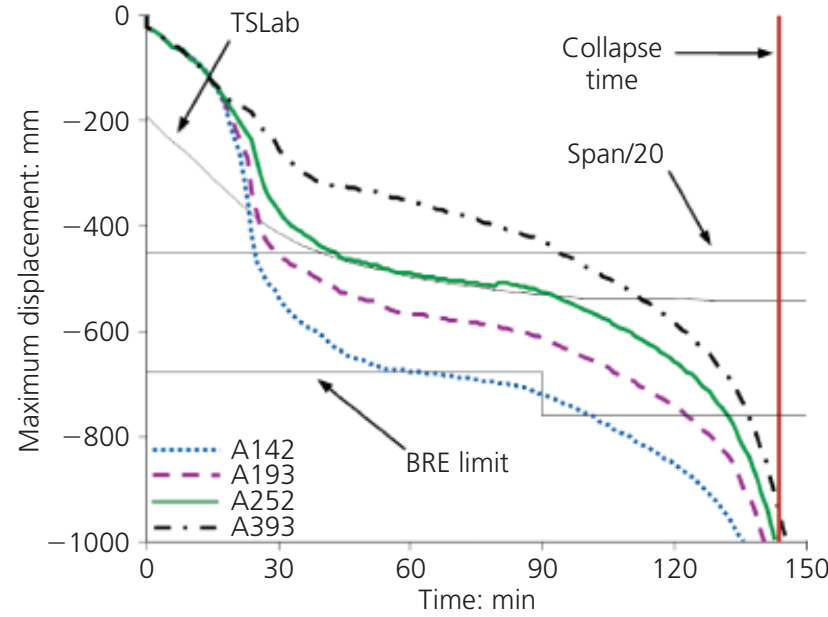

Figure 12. Vulcan $-9 \mathrm{~m} \times 12 \mathrm{~m}$ slab panel central vertical displacements (R120)

so far, slab panels (composite beam-slab systems) have been discussed. The slab behaviour is therefore the result of contributions from both the reinforcement and the composite beams. An attempt is now made to quantify the effects of reinforcement alone on slab capacity at elevated temperatures. Figure 13(a) shows the variation of the central tensile area of three square concrete slabs $(6 \mathrm{~m} \times 6 \mathrm{~m}, 9 \mathrm{~m} \times 9 \mathrm{~m}$ and $12 \mathrm{~m} \times 12 \mathrm{~m})$ with reinforcement area. The results are shown for a span/deflection ratio of 20. The slabs are $120 \mathrm{~mm}$ thick, have an isotropic reinforcement mesh at an average depth of $60 \mathrm{~mm}$ from the top surface of the slab, support a load of $3.11 \mathrm{kN} / \mathrm{m}^{2}$, and are supported on simple vertical supports. The slabs have the same reinforcement yield strength of $500 \mathrm{MPa}$. The reinforcement mesh sizes are 142, 166, 221, 252, 284, 318, 354 and $393 \mathrm{~mm}^{2} / \mathrm{m}$ in each orthogonal direction. The results are obtained by examining the membrane traction results in the Vulcan (Huang et al., 2003a, 2003b, 2004a) analyses, and determining the transition points between tensile and compressive tractions. In Figure 13 the radius of the tensile traction for each reinforcement area is indicated by triangles for $12 \mathrm{~m} \times 12 \mathrm{~m}$; squares for $9 \mathrm{~m} \times 9 \mathrm{~m}$ and diamonds for $6 \mathrm{~m} \times 6 \mathrm{~m}$ slabs. Third-order polynomials are then fitted to the data to observe the trends. From Figure 13(a), the $9 \mathrm{~m} \times 9 \mathrm{~m}$ and $12 \mathrm{~m} \times 12 \mathrm{~m}$ slabs show that the radius of the tensile region reduces with increasing reinforcement area, while the $6 \mathrm{~m} \times 6 \mathrm{~m}$ slab indicates the opposite. Figure 13(b) is a normalised form of the same results, which confirms this observation and further indicates that, beyond a $280 \mathrm{~mm}^{2} / \mathrm{m}$ mesh, the increase in reinforcement area has a negligible effect on the extent of the central area, and hence on the tensile capacity of the slab. Figure 13(c) suggests an explanation of this behaviour. It shows the yield-line failure loads and the corresponding membrane enhancements at the times when the individual slabs attain a span/deflection ratio of 20 . It can be seen that most of the $9 \mathrm{~m} \times 9 \mathrm{~m}$ and $12 \mathrm{~m} \times 12 \mathrm{~m}$ slabs had yield-line failure loads below the applied loading $\left(3.11 \mathrm{kN} / \mathrm{m}^{2}\right)$, and therefore required significant enhancement to carry them. The results

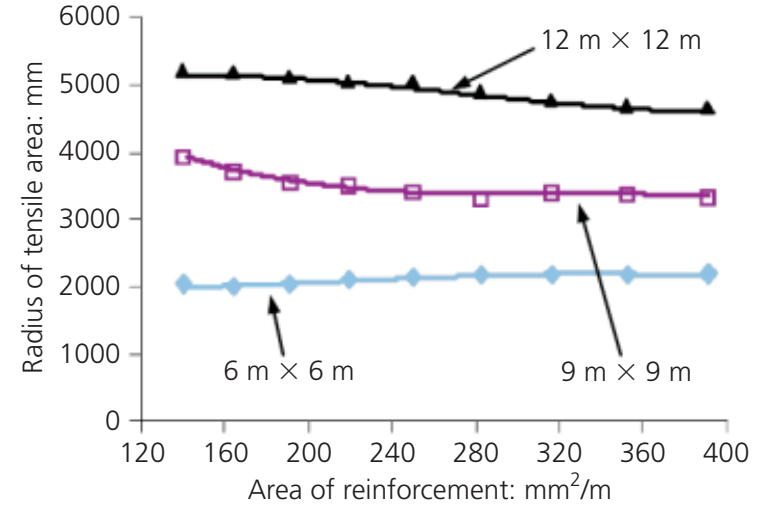

(a)

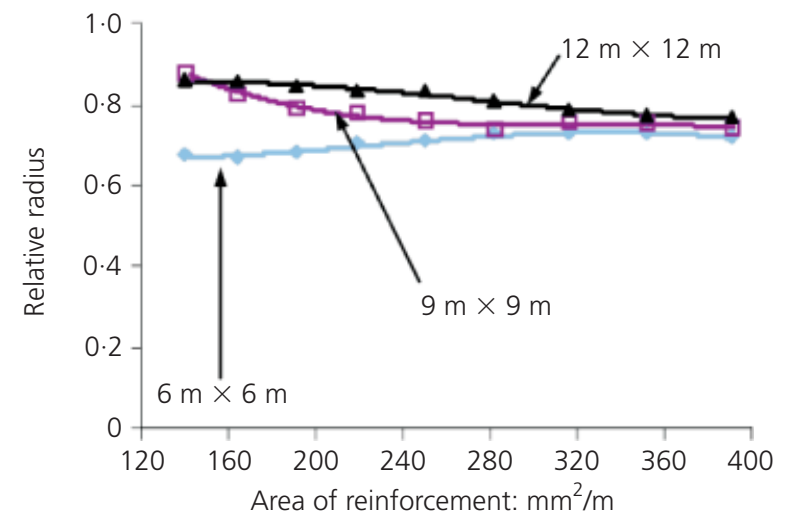

(b)

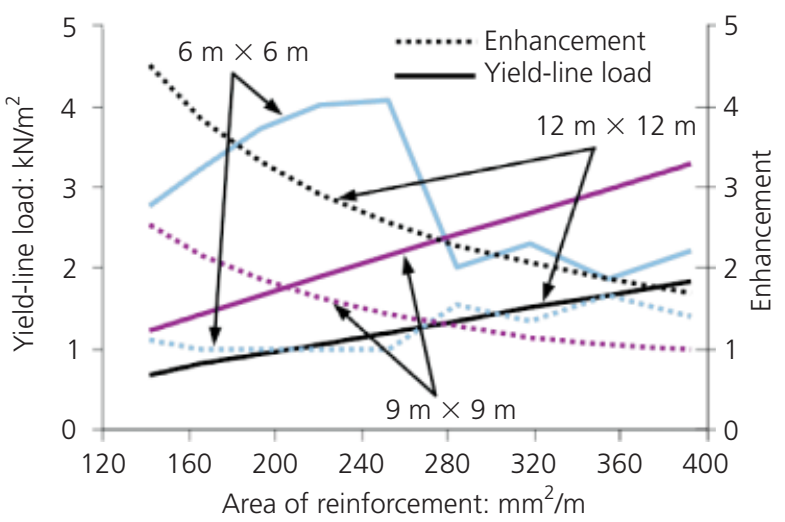

(c)

Figure 13. (a) Vulcan - variation of radius of central tensile area with reinforcement area. (b) Vulcan - normalised variation of radius of central tensile area with reinforcement area. (c) Yieldline loads and enhancement factors for the slab results in Figures 13(a) and 13(b)

in Figures 13(a) and 13(b), therefore, indicate that these slabs need to achieve large deflections to generate the membrane capacity required to bear the applied load. With each increase in reinforcement area, the need for this enhancement reduces, and therefore, the membrane capacity required to attain 'span/20' deflection also reduces. With the $6 \mathrm{~m} \times 6 \mathrm{~m}$ slab, however, the context differs. The yield-line failure loads are increasingly 
higher than those required to carry the applied load, until significant reductions in the reinforcement tensile strength force reductions in yield strengths beyond a reinforcement area of $250 \mathrm{~mm}^{2} /$ $\mathrm{m}$. The temperature of the $284 \mathrm{~mm}^{2} / \mathrm{m}$ reinforcement is $614^{\circ} \mathrm{C}$ at the point when the deflection of that slab reaches $300 \mathrm{~mm}$ (span/ 20). The significant loss in yield strength thereafter requires a higher reinforcement area to generate the required $3 \cdot 11 \mathrm{kN} / \mathrm{m}^{2}$ load capacity. Figure 13, therefore, suggests that for 'small' slabs an increase in reinforcement area has a positive influence on the slab's capacity (but heavy reinforcement makes little contribution), while large reinforcement areas are required, by default, for larger slabs.

\section{Conclusion}

The analyses and comparisons made in this investigation confirm a discrepancy between the original Bailey-BRE method and its development to TSLab, in their interpretation of deflection limits. The results also show that, even after recent development, the Bailey-BRE method loses its conservatism with higher reinforcement ratios. The method's reliance on calculating the deflection required to enhance the traditional yield-line capacity, without adequate consideration of the stability of the edge beams, results in very optimistic predictions of slab panel resistance with larger mesh sizes. On the other hand, the finite-element analyses show that, when load redistributions, aspect ratios and edge beam deflections are considered, only marginal increases in slab panel capacity are obtained with increasing reinforcement size, and the slab panel eventually fails by edge beam failure. The simple edge beam collapse mechanism is found to give accurate predictions of slab panel runaway failure. The comparison indicates that this mechanism needs to be added to the Bailey-BRE method, since edge beams do not stay cold throughout a fire.

Further analyses of the effect of reinforcement size on slab panel capacities reveals that, for small-sized panels and lower fire resistance requirements, increasing reinforcement size does not significantly increase the panel capacity. However, it is simply logical that larger mesh sizes are required for large panels. Higher reinforcement ratios are also required for slabs designed for longer fire resistance periods, in order to resist the high initial thermal bending that occurs. In terms of membrane enhancement, however, increasing the mesh size has little influence.

\section{Acknowledgements}

The authors would like to acknowledge the Overseas Research Studentship Award Scheme, the University of Sheffield and Corus PLC, which collectively funded this project.

\section{REFERENCES}

Abu AK (2009) Behaviour of Composite Floor Systems in Fire. $\mathrm{PhD}$ thesis, University of Sheffield, Sheffield, UK.

Abu AK, Burgess IW and Plank RJ (2008) Slab panel vertical support and tensile membrane action in fire. Steel and Composite Structures 8(3): 217-230.
Bailey CG (2000) Design of Steel Structures with Composite Slabs at the Fire Limit State. The Building Research Establishment, Garston, UK, Final Report No. 81415, for DETR and SCI.

Bailey CG (2001) Steel Structures Supporting Composite Floor Slabs: Design for Fire. The Building Research Establishment, Garston, UK, BRE Digest 462.

Bailey CG (2003) Efficient arrangement of reinforcement for membrane behaviour of composite floors in fire conditions. Journal of Constructional Steel Research 59(7): 931-949.

Bailey CG and Moore DB (2000) The structural behaviour of steel frames with composite floor slabs subject to fire: Part 1: Theory. The Structural Engineer 78(11): 19-27.

Bailey CG and Toh WS (2007a) Behaviour of concrete floor slabs at ambient and elevated temperatures. Fire Safety Journal 42(6-7): 425-436.

Bailey CG and Toh WS (2007b) Small-scale concrete slab tests at ambient and elevated temperatures. Engineering Structures 29(10): 2775-2791.

BSI (1987) BS 476: Part 21: Fire tests on building materials and structures: Method for determination of the fire resistance of load bearing elements of construction. BSI, London, UK.

BSI (1990) BS 5950: Part 3: Structural use of steelwork in building: Design in composite construction. BSI, London, UK.

BSI (2003) BS 5950: Part 8: Structural use of steelwork in building: Code of practice for fire resistant design. BSI, London, UK.

BSI (2005) BS EN1994: Parts 1-2: Design of composite steel and concrete structures: General rules - Structural fire design. BSI, London, UK.

Foster SJ (2006) Tensile Membrane Action of Reinforced Concrete Slabs at Ambient and Elevated Temperatures. PhD thesis, University of Sheffield, Sheffield, UK.

Foster SJ, Bailey CG, Burgess IW and Plank RJ (2004) Experimental behaviour of concrete floor slabs at large displacements. Engineering Structures 26(9): 1231-1247.

Huang Z, Platten A and Roberts J (1996) Non-linear finite element model to predict temperature histories within reinforced concrete in fires. Building and Environment 31(2): $109-118$

Huang Z, Burgess IW, Plank RJ and Bailey CG (2002) Comparison of BRE simple design method for composite floor slabs in fire with non-linear FE modelling. Proceedings of the 2nd International Workshop on Structures in Fire, Christchurch, New Zealand, vol. 1, pp. 83-94.

Huang Z, Burgess IW and Plank RJ (2003a) Modelling membrane action of concrete slabs in composite buildings in fire. I: Theoretical development. Journal of Structural Engineering, ASCE 129(8): 1093-1102.

Huang Z, Burgess IW and Plank RJ (2003b) Modelling membrane action of concrete slabs in composite buildings in fire. II: Validations. Journal of Structural Engineering, ASCE 129(8): 1103-1112.

Huang Z, Burgess IW and Plank RJ (2004a) 3D modelling of beam-columns with general cross-sections in fire. 
Proceedings of the 3rd International Workshop on Structures in Fire, Ottawa, Canada, vol. 1, pp. 323-334.

Huang Z, Burgess IW and Plank RJ (2004b) Fire resistance of composite floors subjected to compartment fires. Journal of Constructional Steel Research 60(2): 339-360.

Newman GM, Robinson JT and Bailey CG (2006) Fire Safe Design: A New Approach to Multi-Storey Steel-Framed
Buildings, 2nd edn. The Steel Construction Institute, Ascot, UK, SCI Publication P288.

Toh WS and Bailey CG (2007) Comparison of simple and advanced models for predicting membrane action on long span slab panels in fire. Proceedings of the 11th International Fire Science and Engineering Conference (Interflam 2007), London, UK, pp. 791-796

\section{WHAT DO YOU THINK?}

To discuss this paper, please email up to 500 words to the editor at journals@ice.org.uk. Your contribution will be forwarded to the author(s) for a reply and, if considered appropriate by the editorial panel, will be published as a discussion in a future issue of the journal.

Proceedings journals rely entirely on contributions sent in by civil engineering professionals, academics and students. Papers should be 2000-5000 words long (briefing papers should be 1000-2000 words long), with adequate illustrations and references. You can submit your paper online via www.icevirtuallibrary.com/content/journals, where you will also find detailed author guidelines. 